\title{
COMPARISON OF TEST METHODS TO ASSESS POZZOLANIC ACTIVITY
}

\author{
S. Donatello, M. Tyrer and C.R. Cheeseman* \\ Centre for Environmental Control and Waste Management, \\ Department of Civil and Environmental Engineering, Skempton Building, \\ Imperial College, London, SW7 2AZ, UK
}

\begin{abstract}
Assessment of the pozzolanic activity of cement replacement materials is increasingly important because of the need for more sustainable cementitious products. The pozzolanic activity of metakaolin, silica fume, coal fly ash, incinerated sewage sludge ash and sand have been compared using the Frattini test, the saturated lime test and the strength activity index test. There was significant correlation between the strength activity index test and the Frattini test results, but the test results from these tests did not correlate with the saturated lime test results. The weight ratio of $\mathrm{Ca}(\mathrm{OH})_{2}$ to test pozzolan is an important parameter. In the Frattini test and strength activity index test the ratio is approximately $1: 1$, whereas in the saturated lime test the ratio is $0.15: 1$. This explains why the saturated lime test shows higher removal of $\mathrm{Ca}(\mathrm{OH})_{2}$ and why the results from this test do not correlate with the other test methods.
\end{abstract}

Keywords: Pozzolan; Portland cement; Sustainable development; Sewage sludge ash; Metakaolin; Silica fume; Pulverised fuel ash; Frattini test

\section{INTRODUCTION}

A pozzolan is defined as (ASTM C125) "a siliceous and aluminous material which, in itself, possesses little or no cementitious value but which will, in finely divided form in the presence of moisture, react chemically with calcium hydroxide at ordinary temperature to form compounds possessing cementitious properties".

Pozzolans were the first cementitious materials used by early civilisations and some of the most important historical buildings rely on pozzolanic cement systems. Pozzolans are of increasing interest because their use reduces overall environmental impact and cost when mixed with Portland cement (CEM-I) in blended cement systems. The use of pozzolans reduces the carbon dioxide emitted per tonne of product and can also improve various physical properties of the resulting concrete [1].

Pozzolans are obtained from various sources and can be naturally occurring minerals or industrial byproducts. They do not necessarily interact with Portland cement in the same way, and the mechanisms involved in hydration of coal fly ash (FA) and silica fume to form hydration products are different. A major benefit of blended cements is improved durability and this occurs because the reaction between the pozzolan and excess $\mathrm{Ca}(\mathrm{OH})_{2}$ produced by CEM-I hydration forms calcium silicate hydrate $(\mathrm{C}-\mathrm{S}$ $\mathrm{H})$ gel, which reduces the porosity of the binder.

A wide range of test methods for assessing pozzolanic activity have been reported in the literature. These can be categorised as either direct or indirect methods. Direct methods monitor the presence of $\mathrm{Ca}(\mathrm{OH})_{2}$ and its subsequent reduction in abundance with time as the pozzolanic reaction proceeds, using analytical methods such as X-ray diffraction (XRD), thermo-gravimetric analysis (TGA) or classical chemical titration.

The Frattini test is a commonly used direct method that involves chemical titration to determine the dissolved $\mathrm{Ca}^{2+}$ and $\mathrm{OH}^{-}$concentrations in a solution containing CEM-I and the test pozzolan. This method has been used to measure the pozzolanic activity of metakaolin [2], catalytic cracking residues [3], crushed bricks [4] and fly ash [5]. 
The saturated lime method is a simplified version of the Frattini test, in which the pozzolan is mixed with saturated lime (slaked lime; $\mathrm{Ca}(\mathrm{OH})_{2}$ ) solution instead of CEM-I and water. The amount of lime fixed by the pozzolan is determined by measuring residual dissolved calcium. Saturated lime test results have been published for paper sludge waste [6], sugar cane straw waste [7, 8] and wastes from the ferroalloy industry [9].

Indirect test methods measure a physical property of a test sample that indicates the extent of pozzolanic activity. This may involve measurement of properties such as compressive strength, electrical conductivity $[7,10,11]$ or heat evolution by conduction calorimetry $[12,13]$. Compressive strength test methods have been used to assess the pozzolanic activity of catalytic cracking residues [14], coal bottom ash [15], glass powders [16], crushed bricks [4], silica fume [13, 17] and sewage sludge ash $[18,19]$. Results from an indirect pozzolanic activity test are often corroborated using direct tests to confirm that pozzolanic reactions are occurring $[14,20]$.

The objective of this research was to assess if different test methods for pozzolanic activity correlate with each other. Three pozzolanic activity test methods have been used to assess the pozzolanic activity of five different test pozzolans, and the results from each test are compared. The direct tests used were the Frattini test and the saturated lime test, and the indirect test used was the strength activity index test. The Frattini test and strength activity test were selected because they have been widely reported and standard procedures exist (BS 3892, EN 196-5 and ASTM C311). The saturated lime test method was selected because it is similar but simpler than the Frattini test and provides quantitative results from a direct test method.

\section{EXPERIMENTAL}

\subsection{Materials and characterisation}

Five different siliceous or aluminosilicate materials were used as test pozzolans. These were: incinerator sewage sludge ash (ISSA, supplied by United Utilities, UK), coal fly ash (FA; Drax power station, UK), metakaolin (MK; Metastar 501, IMERYS Minerals Ltd., UK), silica fume (SF; Elkem Materials Ltd) and silica sand sieved to $<150 \mu \mathrm{m}$. Chemical composition data was provided by the respective suppliers of ISSA, FA, MK and SF.

Loss on ignition (LOI) was measured by oven drying $2-3 \mathrm{~g}$ of material at $105^{\circ} \mathrm{C}$ to constant mass before calcining at $775^{\circ} \mathrm{C}$ for 1 hour, cooling and re-weighing. The $\mathrm{pH}$ was determined by preparing a 5:1 liquid to solid ratio suspension using deionised water. The mixture was shaken for 5 minutes and left for 3 hours to equilibrate before measuring the $\mathrm{pH}$ (BS 7755-3.2). Specific gravity was determined by pycnometry. The particle size distribution was analysed by laser diffraction (Beckman Coulter LS100) over the size range $0.4-900 \mu \mathrm{m}$. Specific surface area and pore size distribution of ISSA was determined by $\mathrm{N}_{2}$ adsorption (Coulter Omnisorp 100) using the Brunauer-Emmett-Teller (BET) method.

The resulting physical and chemical property data of the test pozzolans is summarised in Table 1 and particle size distribution data is given in Figure 1.

\subsection{Pozzolanic activity test methods}

a) Strength Activity Index (SAI)

The procedure used was based on BS 3892. Control mortar blocks were prepared by mixing $1350 \mathrm{~g}$ sand, $450 \mathrm{~g}$ Portland cement and $225 \mathrm{ml}$ water in a planetary orbital mixer for 5 minutes. Test samples were prepared in the same manner, except that $20 \%$ of the Portland cement was replaced with the test pozzolan. Mix compositions are summarised in Table 2. Flow tests were carried out on pastes according to EN 1015-3. The water to binder ratio was altered so that the mixture had the same flow 
properties as the control mortar $(+/-5 \mathrm{~mm})$. Mortar pastes were then remixed for 30 seconds and cast into six $50 \mathrm{~mm}$ cubes with the aid of a vibrating table.

All blocks were de-moulded after 24 hours and placed in a water bath at $23^{\circ} \mathrm{C}$ for 6 or 27 days. They were then removed from the bath, surface dried and tested for 7 or 28 day compressive strength. Strength results reported are the averages of three tests and are presented as percentage strength relative to the control mortar with the strength activity index (SAI) therefore reported as;

$$
S A I=A / B \times 100
$$

where $\mathrm{A}$ is the unconfined compressive strength of the test pozzolan specimen (MPa) and B is the strength of the control mortar (MPa).

According to BS 3892, SAI results greater than 0.80 after 28 days are indicative of a positive pozzolanic activity for FA for a cement replacement of 30\%. ASTM C618 requires a SAI greater than 0.75 after 7 and 28 days for FA and natural pozzolans at a cement replacement of $20 \%$.

\section{b) Frattini Test}

The procedure specified in EN 196-5 was used. 20g test samples were prepared consisting of $80 \%$ PC and $20 \%$ of the test pozzolan and mixed with $100 \mathrm{ml}$ of distilled water. After preparation, samples were left for 8 days in a sealed plastic bottle in an oven at $40^{\circ} \mathrm{C}$. After 8 days, samples were cooled to ambient temperature and vacuum filtered through a $2.7 \mu \mathrm{m}$ nominal pore size filter paper (Whatman no. 542). The filtrate was analysed for $\left[\mathrm{OH}^{-}\right]$by titration against dilute $\mathrm{HCl}$ with methyl orange indicator and for $\left[\mathrm{Ca}^{2+}\right]$ by $\mathrm{pH}$ adjustment to 12.5 , followed by titration with $0.03 \mathrm{M}$ EDTA solution using Patton and Reeders indicator.

Results are presented as a graph of $\left[\mathrm{Ca}^{2+-}\right.$ - expressed as equivalent $\left.\mathrm{CaO}\right]$ in $\mathrm{mmol}$ on the $\mathrm{y}$-axis versus $\left[\mathrm{OH}^{-}\right]$in mmol on the x-axis. The solubility curve of $\mathrm{Ca}(\mathrm{OH})_{2}$ is plotted and a control sample of $100 \%$ CEM-I is compared to ensure that this result lies on the same saturation curve. Test results lying below this line indicate removal of $\mathrm{Ca}^{2+}$ from solution which is attributed to pozzolanic activity. Results lying on the line are indicative of zero pozzolanic activity and results above the line correspond to no pozzolanic activity. It should be noted that this procedure assumes no other source of soluble calcium is present in the system, as leaching of calcium would invalidate this approach.

\section{c) Saturated Lime Test}

During CEM-I hydration $\mathrm{Ca}(\mathrm{OH})_{2}$ is precipitated as the mineral portlandite. In the presence of a pozzolan, the $\mathrm{Ca}(\mathrm{OH})_{2}$ reacts with the pozzolan. This shift in equilibrium allows more solid $\mathrm{Ca}(\mathrm{OH})_{2}$ to dissolve, until either the pozzolan or portlandite is exhausted. A much simpler approach is used in the saturated lime test [6-8], in which a fixed quantity of $\mathrm{Ca}(\mathrm{OH})_{2}$ is available in solution. Samples were prepared with $1 \mathrm{~g}$ of pozzolan added to a plastic bottle containing $75 \mathrm{ml}$ of saturated lime solution. The lime solution was prepared by dissolving $2 \mathrm{~g}$ of hydrated lime (Limbux, a high calcium hydrated lime, Buxton Lime Industries Ltd., Buxton UK) in 1 litre of distilled water. The bottles were then sealed and placed in an oven at $40^{\circ} \mathrm{C}$ for $1,3,7$ and 28 days. Samples were then filtered and titrated for $\left[\mathrm{OH}^{-}\right]$and $\left[\mathrm{Ca}^{2+}\right]$ using the same procedure as in the Frattini test. As the quantity of $\mathrm{Ca}^{2+}$ ions is accurately known at the beginning of the test and because $\mathrm{Ca}^{2+}$ ions only interact with the test material or water, the quantity of lime fixed by the test materials can be quantified. Results are reported as mmol $\mathrm{CaO}$ fixed or $\%$ total $\mathrm{CaO}$ fixed per gram of test pozzolan. It is interesting to note that the solubility of portlandite is governed by its negative heat of solution (i.e. its solubility falls as temperature increases) so presumably some of the $\mathrm{Ca}(\mathrm{OH})_{2}$ dissolved at room temperature will initially precipitate at $40^{\circ} \mathrm{C}$, before re-dissolving and reacting with the pozzolan. Nonetheless, the absolute quantity of $\mathrm{Ca}(\mathrm{OH})_{2}$ in the system is fixed and the elevated temperature ensures prompt reaction with the pozzolan.

\section{RESULTS}




\subsection{Strength activity index test}

The results are reported as averages of 3 replicates. The control mortar strength was $39.9 \mathrm{MPa}$ at 7 days and $49.6 \mathrm{MPa}$ at 28 days. Figure 2 shows that all test pozzolans cause a decrease in strength after 7 days relative to the control. After 28 days, with the exception of MK samples, there is still a clear difference between control and test sample strength. If the test pozzolans were completely inert, there should be a decrease of $20 \%$ in the strength development due to the dilution effect. However, strength is related to other factors than simply the cement content. In particular, permeability, porosity and hydration reaction kinetics all influence strength development. For the purposes of this study, the sand samples are treated as an inert control and assumed as a baseline for zero pozzolanic activity. With this assumption, it may be concluded that ISSA shows no pozzolanic activity, FA and SF show only slight pozzolanic activity and MK shows considerable pozzolanic activity.

\subsection{Frattini Test}

The results are reported in duplicate. Figure 3 indicates that samples containing 80\% CEM-I and 20\% test pozzolan, FA, SF and MK show pozzolanic activity, whereas sand and ISSA are inactive.

In order to correlate these results with the SL and SAI tests it is necessary to quantify the results from the Frattini tests. This was achieved by considering the distance of data points from the lime solubility curve and from the zero point on the vertical axis at the given $\left[\mathrm{OH}^{-}\right]$. Although this method is only applicable to samples where the measured $\left[\mathrm{OH}^{-}\right]$is between 35 and $90 \mathrm{mmol}$, it can still be applied to

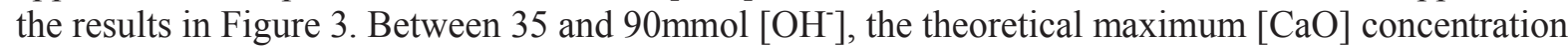
can be calculated using the formula given in EN 196-5 to plot the lime solubility curve:

$$
\operatorname{Max}[\mathrm{CaO}]=\frac{350}{[\mathrm{OH}]-15}
$$

In this way the sample calcium concentration $[\mathrm{CaO}]$ may be compared to the theoretical maximum $[\mathrm{CaO}]$ and the result quantified as the difference between the two values. Finally, this is expressed as a percentage of the theoretical maximum removed, as in Table 3.

These results show that ISSA and sand are not pozzolanic. The negative value of $\% \mathrm{CaO}$ removal for sand and ISSA samples are surprising as in both cases the amount of calcium in solution appears greater than expected. In theory, any solid precipitated $\mathrm{Ca}(\mathrm{OH})_{2}$ crystals present should be retained on the filter. Results above the solubility curve imply that either some suspended $\mathrm{Ca}(\mathrm{OH})_{2}$ or CSH gel has passed the through filter and/or there is experimental error in the titration procedure. Negative results should be normalised to $0 \%$ equivalent $\mathrm{CaO}$ removal. This approach shows that the pozzolanic activity of MK is very high with $94 \%$ lime removal, FA is considerable with $47 \%$ lime removal and $\mathrm{SF}$ is also active but to a reduced extent, with $35 \%$ lime removal.

\subsection{Saturated Lime Test}

The SL test results are easily quantified due to the simplicity of the system. A controlled quantity of lime is added at the beginning of the test and the residual lime in solution is measured at the end. The difference is due to lime being fixed by the solid test material and retained on the filter paper. It would be expected that the control sample, containing only saturated lime solution and sand should show a zero result for fixed lime. However this was not the case and it was found that the initial quantity of lime added ( $2 \mathrm{~g}$ equivalent to $20.45 \mathrm{mmol} / \mathrm{L}$ ) exceeded the solubility of lime by $0.3 \mathrm{~g}$ or $\sim 3.0 \mathrm{mmol} / \mathrm{L}$. Therefore when control or inactive samples were filtered the excess lime, which is present as precipitated lime, is removed by the filter paper, although the results suggest it was removed by reaction with sand. For this reason the control sample should be used as a zero activity baseline. This is potentially a serious shortcoming of this method. The solubility of $\mathrm{Ca}(\mathrm{OH})_{2}$ varies with temperature, so any stock solution must be kept at constant temperature and free of $\mathrm{CO}_{2}$. 
It is important to note that for samples with a positive fixation of lime, it is not necessary to subtract the control baseline value. This is because the reservoir of precipitated lime in the starting solution will have been exhausted as the first $\sim 3 \mathrm{mmol} / \mathrm{L}$ lime is fixed by the test material. Saturated lime test results are summarised in Figure 4.

Accounting for the control baseline it is clear that sand is non-reactive with lime and therefore not pozzolanic. There is a difference between materials in the rate of lime fixation during the first three days. ISSA and SF remove lime the fastest, whereas FA shows no removal above the baseline control. However after 7 days, there are no significant differences between ISSA, FA, MK or SF in terms of lime fixation and all materials fixed around $90 \%$ of the total available lime.

\subsection{Correlation between methods}

From the correlation graphs in Figures 5-7 it is clear that there is a significant correlation $\left(\mathrm{R}^{2}=0.86\right)$ between the SAI results and the Frattini test results. However there is no correlation between the Frattini test and the SL test or between the SAI test and the SL test, even when considering the SL results at $1,3,7$ or 28 days.

\section{DISCUSSION}

When assessing the pozzolanic activity of a material, it is important to take into account the method used. While it is common for pozzolanic activity to be investigated by more than one method, at least one of the methods is likely to be qualitative and show a trend of $\mathrm{Ca}(\mathrm{OH})_{2}$ consumption with time. When comparing different methods a key consideration is the temperature and time of sample curing prior to testing. The SAI test is specified for 28 days at $23^{\circ} \mathrm{C}$ and the Frattini test for 8 days at $40^{\circ} \mathrm{C}$. However the SL test can be carried out at different times because there is no need to wait for cement hydration reactions to proceed.

Perhaps the most important factor when comparing tests is the lime: pozzolan weight ratio. With PC hydration it is difficult to accurately know what quantity of $\mathrm{Ca}(\mathrm{OH})_{2}$ is produced, although as a rule $25 \%$ of the original cement mass is present as $\mathrm{Ca}(\mathrm{OH})_{2}$ after complete hydration. Therefore in the Frattini and SAI tests where, for every $2 \mathrm{~g}$ of pozzolan there was $8 \mathrm{~g}$ of cement, a $1: 1$ weight ratio can be assumed. In the SL test, $1 \mathrm{~g}$ of pozzolan was mixed with $75 \mathrm{~mL}$ of saturated lime solution containing a total of $0.15 \mathrm{~g} \mathrm{Ca}(\mathrm{OH})_{2}$, giving a much lower lime: pozzolan ratio of 0.15: 1 .

Due to the lower lime: pozzolan ratio, the SL test is therefore preferably disposed to showing positive pozzolanic activities compared to the Frattini test. The most pronounced difference between the tests was for ISSA, where the SL test showed a highly positive result whereas the Frattini test showed zero activity. The SL test results indicate that ISSA is capable of removing finite quantities of lime from solution very rapidly, but that the mechanism is limited in capacity. The Frattini test results suggest that the same mechanism does not occur in a super-saturated lime solution as produced by cement hydration. This may in part reflect the differences between a saturated $\mathrm{Ca}(\mathrm{OH})_{2}$ solution and CEM-I pore fluid. In the latter, the presence of alkali metal ions $\left(\mathrm{Na}^{+}\right.$and $\left.\mathrm{K}^{+}\right)$suppress the solubility of calcium hydroxide from around $20 \mathrm{mM}$ in water to $1-5 \mathrm{mM}$ depending on the alkali activity. Additionally, the $\mathrm{pH}$ of CEM-I solutions is somewhat higher $(\mathrm{pH}>13)$ than the equilibrium value $(\sim$ $\mathrm{pH}$ 12.4) of portlandite alone, balanced by $\mathrm{Na}^{+}$and $\mathrm{K}^{+}$ions. It seems reasonable to suppose that the pozzolanic reaction in the Frattini method would involve the alkali metals in addition to portlandite. Certainly as hydration progresses, the portlandite initially present in blended cements re-dissolves and participates in further C-S-H production and it would seem reasonable to expect a similar mechanism here.

\section{Comparison of the Frattini test with the Saturated Lime (SL) test}

The results show that the SL test has reached a stable equilibrium after 7 days given that all materials show similar pozzolanic activity with the notable exception of sand, which remained inert throughout. 
The inertness of sand is vital, as it helps discount the possibility that $\mathrm{Ca}(\mathrm{OH})_{2}$ removal from solution is simply an adsorption phenomenon. The SL test gives a positive pozzolanic activity for ISSA although the Frattini test gives a negative result. Because there is 6-7 times less $\mathrm{Ca}(\mathrm{OH})_{2}$ in the SL test it is possible that the pozzolanic capacity of ISSA is not yet exceeded as in the Frattini test. The cation exchange capacity of ISSA may be sufficient to remove most of the calcium from solution in exchange for $\mathrm{Na}^{+}$and $\mathrm{K}^{+}$. It is possible that if the weight of pozzolan in the SL test was reduced so that the pozzolan: $\mathrm{Ca}(\mathrm{OH})_{2}$ weight ratio was 1: 1 then a negative SL test result for ISSA could arise. As with ISSA, all other test materials except sand had high pozzolanic activity in the SL test after 7 days. With the Frattini test, sand and ISSA were inert, and there was a significant difference between the pozzolanic activity of MK, FA and SF. Consequently, there was no correlation between the SL and Frattini tests.

\section{Comparison of the Strength Activity Index (SAI) test and the Frattini test}

As both of these tests specify a percentage of pozzolan mixed with PC, it was decided that it is best to compare identical cement replacement rates, in this case 20\%. The Frattini test results provide an insight into the likely $\mathrm{Ca}(\mathrm{OH})_{2}$ concentration in the pore solution of SAI blocks. From the Frattini test it was evident that $20 \%$ ISSA was not sufficient to decrease the $\mathrm{Ca}(\mathrm{OH})_{2}$ solution concentration. Therefore it is not surprising that SAI blocks containing 20\% ISSA showed no additional strength development compared to the inert control samples using sand as the test pozzolan. For both methods, MK showed the highest activity, and it can be concluded that the removal of $\mathrm{Ca}(\mathrm{OH})_{2}$ from solution in the Frattini test at a high level after 8 days indicates that after 28 days in the SAI test, sufficient reaction between $\mathrm{MK}$ and pore solution $\mathrm{Ca}(\mathrm{OH})_{2}$ occurs to form strength providing C-S-H gel type phases. There is a significant correlation between results from these two tests.

\section{Comparison of SAI test with SL test}

The SL tests show nearly identical pozzolanic activity for ISSA, SF, MK and FA. However the SAI test shows a low result for ISSA and sand, mediocre results for FA and SF, and a highly positive result for MK. Therefore it is unsurprising that no correlation exists between the procedures. Differences are likely to stem from the fact that the SL test uses a different chemical system. No cement is involved in the SL test and no bulk solid phase is formed as is the case in the SAI and Frattini tests.

Furthermore the SAI results are skewed due to the water requirement of the mixture. For example the water requirement of SAI mixes to obtain the control flow spread differed significantly between test pozzolans as shown in Table 2. MK had the highest water requirement followed by SF and ISSA. According to hydration stoichiometry, a w/c ratio of $\sim 0.23$ is required to completely hydrate PC. This would be equivalent to a water addition of $103.5 \mathrm{ml}$. However the control SAI mortar used $225 \mathrm{ml}$ water and SF samples used $296 \mathrm{ml}$ water. Excess water in a cement paste will eventually bleed or evaporate from the block, leaving behind pores which are detrimental to the strength of the matrix. The scale of the effect due to water content relative to the effect of any pozzolanic reaction is unknown and should be the subject of further work.

Finally the confidence with which calcium hydroxide solubility may be measured or predicted, the effect of temperature on this property and the implications for this work are considered. It has already been noted that a small quantity of solid $\mathrm{Ca}(\mathrm{OH})_{2}$ passing the filter will have a large buffering effect in a subsequent titration and introduce correspondingly large errors. Consequently, we decided to compare the results of other workers with thermodynamic estimates of portlandite solubility. Figures 8 and 9 show the predicted solubility and $\mathrm{pH}$ of portlandite in water over the temperature interval 5 to $45^{\circ} \mathrm{C}$, calculated using the thermodynamic code PHREEQC-I (version 13) [21]. The calculations have been performed using those databases supplied with the code which contain data for portlandite. In addition, data from the HATCHES database (version 14) have been included [22]. As noted above, the negative heat of solution of this phase causes a fall in solubility with rising temperature. What is more surprising is the relatively large scatter of the predicted results, especially as a function of temperature. At $23^{\circ} \mathrm{C}$ there is general agreement between the databases that the solubility of $\mathrm{Ca}(\mathrm{OH})_{2}$ is $22 \mathrm{mM}$ $\pm 1 \mathrm{mM}$, which seems reasonable in light of our $\mathrm{pH}$ and [Ca] measurements. The Lawrence Livermore data disagree with this by $6.8 \mathrm{mM}$, equivalent to a $31 \%$ underestimate, which warrants investigation 
outside of this study. At $40^{\circ} \mathrm{C}$, the temperature of the saturated lime and Frattini tests, the predicted solubility of $\mathrm{Ca}(\mathrm{OH})_{2}$ is reduced by between $12.5 \%$ and $45.0 \%$ of its value at $23^{\circ} \mathrm{C}$. These predictions have two implications; measured values of $\mathrm{pH}$ and $[\mathrm{Ca}]$ are probably correct and the anomalous estimates of calcium uptake reflect shortcomings of the test methods, rather than the analyses. The second implication is that $\mathrm{Ca}(\mathrm{OH})_{2}$ solubility will be considerably greater in the strength activity test than in other methods carried out at elevated temperatures. This is likely to be off-set by an increase in hydration kinetics expected at elevated temperature.

\section{Conclusions}

Important conclusions from this work are:

- $\quad$ MK was the most pozzolanic material according to the Frattini Test and SAI;

- Silica sand was unreactive in all 3 tests;

- ISSA and SF were the most reactive pozzolans as shown by the 1 day SL test;

- MK, SF, ISSA and FA were all highly pozzolanic after 7 days according to the SL test;

- The Frattini test results can be quantified where $\left[\mathrm{OH}^{-}\right]$is in the range $35-90 \mathrm{mmol} / \mathrm{L}$;

- There was significant correlation between the SAI and Frattini test results $\mathrm{R}^{2}=0.86$;

- There was no correlation between the SL test and the SAI or Frattini test;

- A 7 day period is too long to successfully differentiate the pozzolanic activities of MK, ISSA, FA and SF using the SL test;

- The effect of increasing the lime: pozzolan ratio may improve the correlation of test methods with the saturated lime test and should be investigated further;

- The effect of water content on the SAI results is uncertain and should be investigated further.

Although no test method is perfect, the Frattini test and strength activity index test results correlate well with each other and are tightly controlled methods. The saturated lime test has two principal shortcomings. First and foremost, the activator to pozzolan ratio is much less than in the other methods and secondly, uncertainties in the absolute amount of $\mathrm{Ca}(\mathrm{OH})_{2}$ in each sample may introduce errors. Our recommendation would be that the Frattini and SAI methods are used. In combination with an independent determination of $\mathrm{Ca}(\mathrm{OH})_{2}$ content, for example by thermal or diffraction methods, these tests provide a robust assessment of the pozzolanic activity of materials.

\section{Acknowledgements}

This research was carried out as part of an Industrial CASE award research project funded by the UK Engineering and Physical Sciences Research Council (EPSRC) through the Resource Efficiency Knowledge Transfer Network (RE-KTN) supported by Akristos Ltd.

\section{References}

1. Malhotra VM, Kumar Mehta P. Pozzolanic and cementitious materials. Amsterdam: Gordon and Breach Science Publishers, 1996.

2. Talero R. Performance of metakaolin and Portland cements in ettringite formation as determined by ASTM C 452-68: kinetic and morphological differences. Cement and Concrete Research 2005;35:1269-1284.

3. Paya J, Monzo J, Borrachero MV. Physical, chemical and mechanical properties of fluid catalytic cracking catalyst residue (FC3R) blended cements. Cement and Concrete Research 2001;31:57-61.

4. Wild S, Gailius A, Hansen H, Pederson L, Szwabowski J. Pozzolanic properties of a variety of european clay bricks. Building Research and Information 1997;25:170-175.

5. Rahhal V, Talero R. Influence of two different fly ashes on the hydration of portland cements. Journal of Thermal Analysis and Calorimetry 2004;78:191-205. 
6. Garcia R, Vigil de la Villa R, Vegas I, Frias M, Sanchez de Rojas MI. The pozzolanic properties of paper sludge waste. Construction and Building Materials

7. Frias M, Villar-Cocina E, Sanchez de Rojas MI, Valencia-Morales E. The effect that different pozzolanic activity methods has on the kinetic constants of the pozzolanic reaction in sugar cane straw-ash/lime systems: Application of a kinetic-diffusive model. Cement and Concrete Research 2005;35:2137-2142.

8. Frias M, Villar-Cocina E, Valencia-Morales E. Characterisation of sugar cane straw waste as pozzolanic material for construction: Calcining temperature and kinetic parameters. Waste Management 2007;27:533-538.

9. Frias M, Rodriguez C. Effect of incorporating ferroalloy industry wastes as complementary cementing materials on the properties of blended cement matrices. Cement and Concrete Composites 2007;30:212-219.

10. McCarter WJ, Tran D. Monitoring pozzolanic activity by direct activation with calcium hydroxide. Construction and Building Materials 1996;10:179-184.

11. Paya J, Borrachero MV, Monzo J, Peris-Mora E, Amahjour F. Enhanced conductivity measurement techniques for evaluation of fly ash pozzolanic activity. Cement and Concrete Research 2001;31:41-49.

12. Mostafa NY, Brown PW. Heat of hydration of high reactive pozzolans in blended cements: Isothermal conduction calorimetry. Thermochimica Acta 2005;435:162-167.

13. Mostafa NY, El-Hemaly SAS, Al-Wakeef EI, El-Korashy SA, Brown PW. Characterisation and evaluation of the pozzolanic activity of Egyptian industrial byproducts I: Silica fume and dealuminated kaolin. Cement and Concrete Research 2001;31:467-474.

14. Tseng YS, Huang CL, Hsu KC. The pozzolanic activity of a calicined waste FCC catalyst and its effect on the compressive strength of cementitious materials. Cement and Concrete Research 2005;35:782-787.

15. Cheriaf M, Rocha JC, Pera J. Pozzolanic properties of pulverized coal combustion bottom ash. Cement and Concrete Research 1999;29:1387-1391.

16. Shi C, Wu Y, Riefler C, Wang H. Characteristics and pozzolanic reactivity of glass powders. Cement and Concrete Research 2005;35:987-993.

17. Agarwal SK. Pozzolanic activity of various siliceous materials. Cement and Concrete Research 2006;36:1735-1739.

18. Monzo J, Paya J, Borrachero MV, Peris-Mora E. Mechanical behaviour of mortars containing sewage sludge ash (SSA) and Portland cements with different tricalcium aluminate content. Cement and Concrete Research 1999;29:87-94.

19. Pan SC, Tseng DH, Lee CC, Lee C. Influence of the fineness of sewage sludge ash on the mortar properties. Cement and Concrete Research 2003;33:1749-1754.

20. Shi C, Grattan-Bellew PE, Stegemann JA. Conversion of a waste mud into a pozzolanic material. Construction and Building materials 1999;13:279-284.

21. Parkhurst DL, and Appelo, CAJ. User's guide to PHREEQC (Version 2). A computer program for speciation, batch-reaction, one-dimensional transport, and inverse geochemical calculations: U.S. Geological Survey Water-Resources Investigations Report 99-4259, 1999.

22. Bond KA, Heath TG, and Tweed CJ. HATCHES: A Referenced Thermodynamic Database for Chemical Equilibrium Studies. 1997. Nirex Report. Updated database, version 14 (2001) used in this study. 
Figure 1 - Cumulative particle size distribution of as-received test materials

Figure 2 - Strength activity index of five different test materials after 7 and 28 days. Results are averages of triplicate determinations and expressed as \% of control sample strengths, which were 39.9MPa after 7 days and $49.6 \mathrm{MPa}$ after 28 days.

Figure 3 - Frattini test results for 5 test pozzolans after 8 days curing at $40^{\circ} \mathrm{C}$. Test mixtures consisted of $4 \mathrm{~g}$ pozzolan and $16 \mathrm{~g}$ PC in $100 \mathrm{ml}$ distilled water in a sealed plastic bottle. Duplicate samples were prepared and individual results plotted above.

Figure 4 - Saturated lime test results for the 5 test pozzolans after 1, 3, 7 and 28 days of curing in sealed plastic bottles at $40^{\circ} \mathrm{C}$. Each bottle contained $1 \mathrm{~g}$ of test pozzolan and $75 \mathrm{ml}$ of a saturated lime solution $\left(2 \mathrm{~g} \mathrm{Ca}(\mathrm{OH})_{2} / \mathrm{L}\right)$.

Figure 5 - Correlation between measured pozzolanic activity of 5 test materials using the Frattini test and the strength activity index test

Figure 6 - Correlation between measured pozzolanic activity of 5 test materials using the saturated lime test (at 1, 3, 7 and 28d) and the 28d strength activity index test results

Figure 7 - Correlation between measured pozzolanic activity of 5 test materials using the saturated lime test (at 1, 3, 7 and 28d) and the Frattini test at 8d.

Figure 8 - Predicted solubility of portlandite as a function of temperature, using the thermodynamic code PHREEC-I [21] with four published databases: Wateq4f and Minteq4 contain data supplied with software of the same names. Hatches version 16 (UK) [22] is lodged with the Nuclear Energy Agency whilst the data from the Lawrence Livermore National Laboratory (USA) is supplied with the

PHREEQC-I package. 


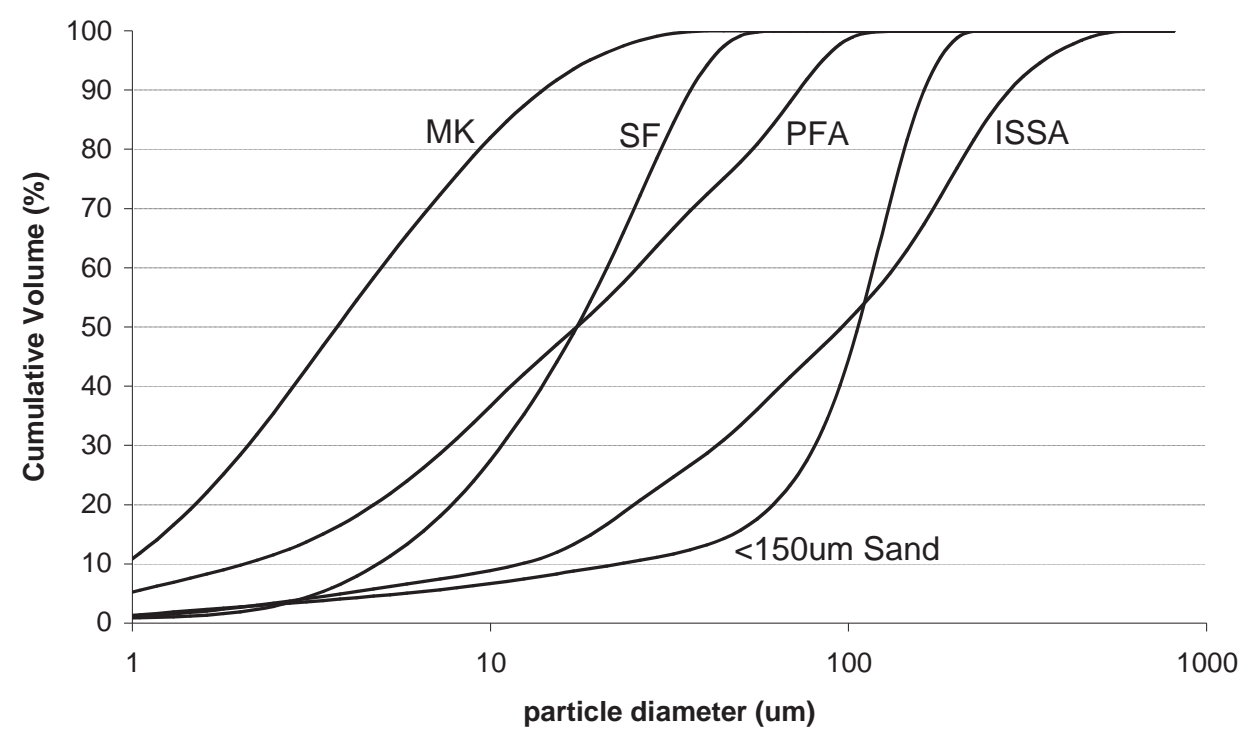

Figure 1 - Cumulative particle size distribution of as-received test materials

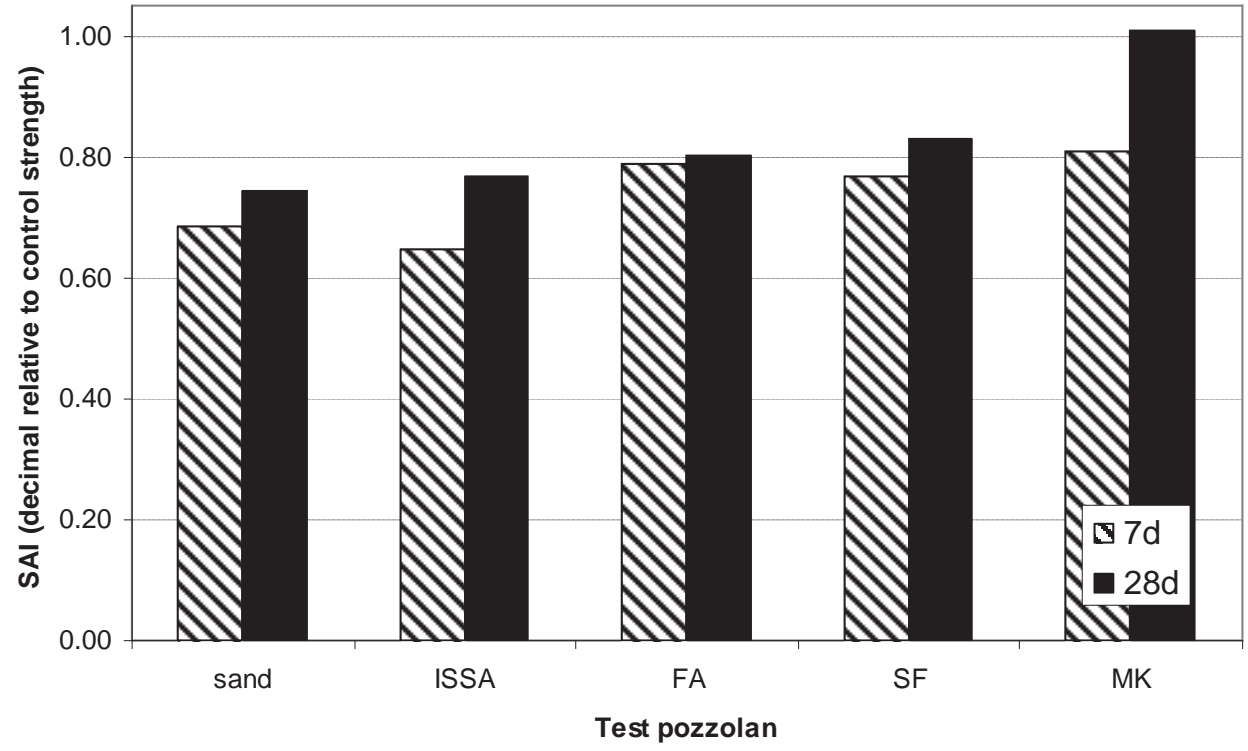

Figure 2 - Strength activity index of five different test materials after 7 and 28 days. Results are averages of triplicate determinations and expressed as \% of control sample strengths, which were 39.9MPa after 7 days and 49.6MPa after 28 days. 


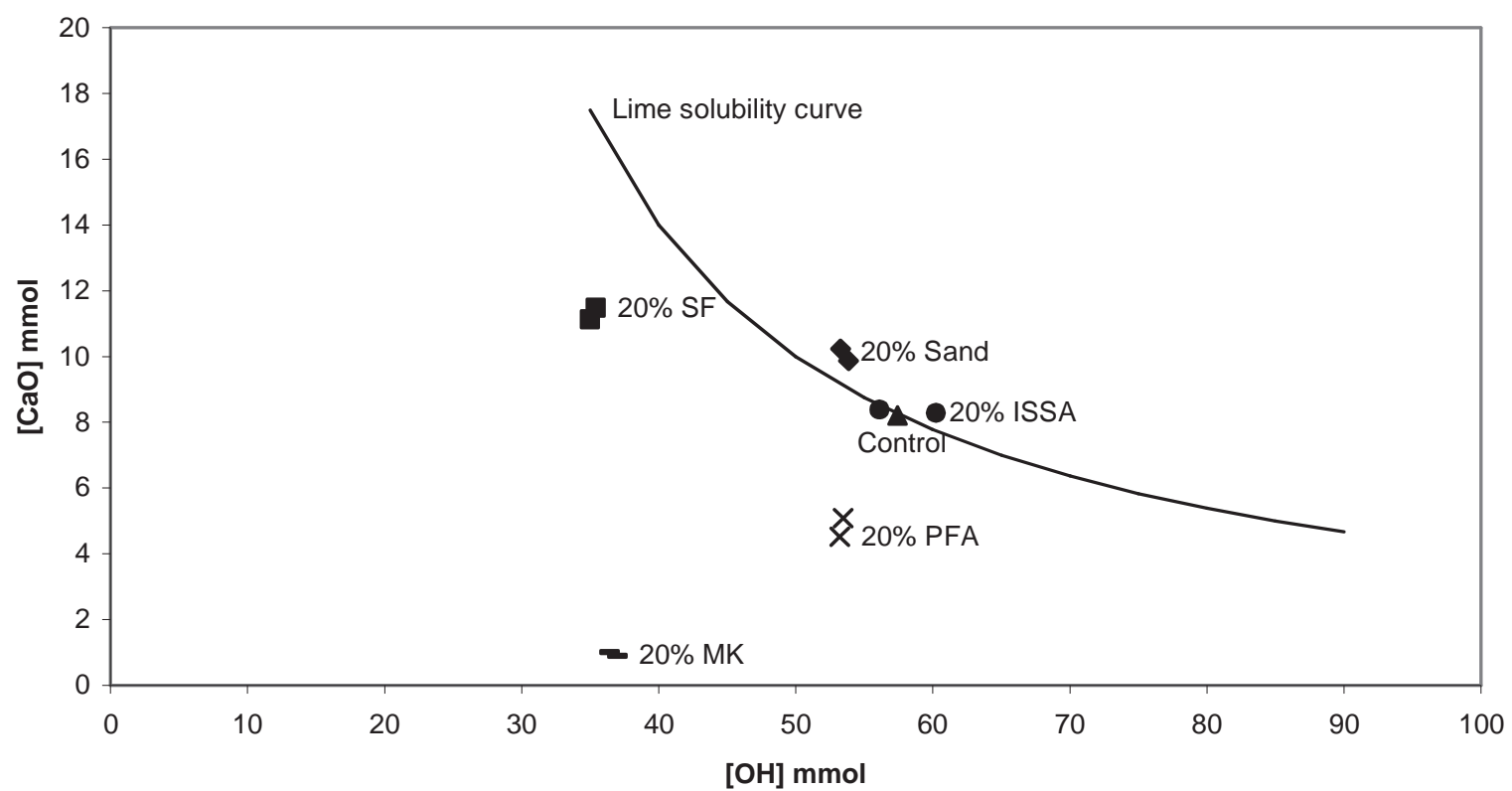

Figure 3 - Frattini test results for 5 test pozzolans after 8 days curing at $40^{\circ} \mathrm{C}$. Test mixtures consisted of $4 \mathrm{~g}$ pozzolan and $16 \mathrm{~g}$ PC in $100 \mathrm{ml}$ distilled water in a sealed plastic bottle. Duplicate samples were prepared and individual results plotted above.

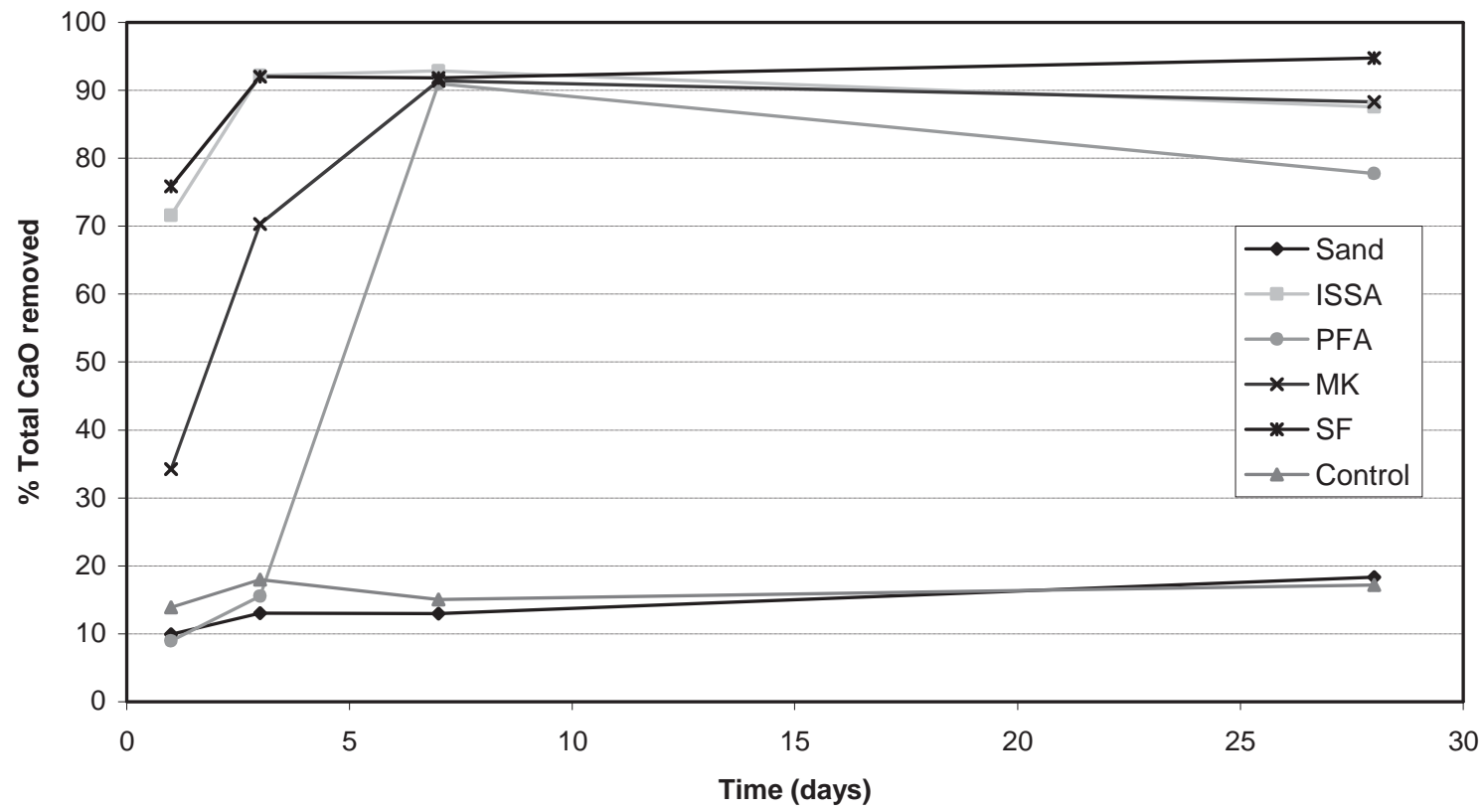

Figure 4 - Saturated lime test results for the 5 test pozzolans after 1, 3, 7 and 28 days of curing in sealed plastic bottles at $40^{\circ} \mathrm{C}$. Each bottle contained $1 \mathrm{~g}$ of test pozzolan and $75 \mathrm{ml}$ of a saturated lime solution $\left(2 \mathrm{~g} \mathrm{Ca}(\mathrm{OH})_{2} / \mathrm{L}\right)$. 


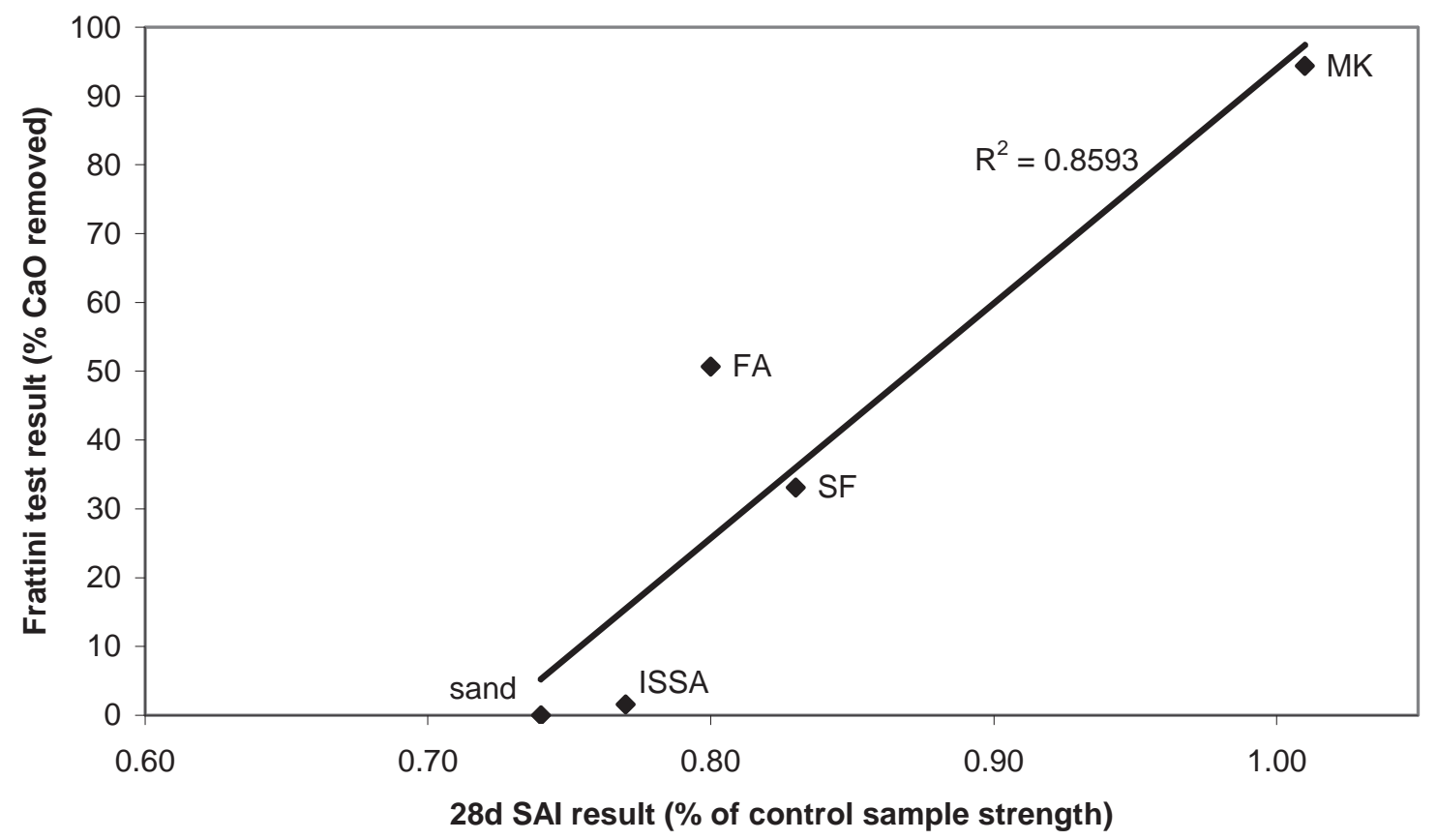

Figure 5 - Correlation between measured pozzolanic activity of 5 test materials using the Frattini test and the strength activity index test

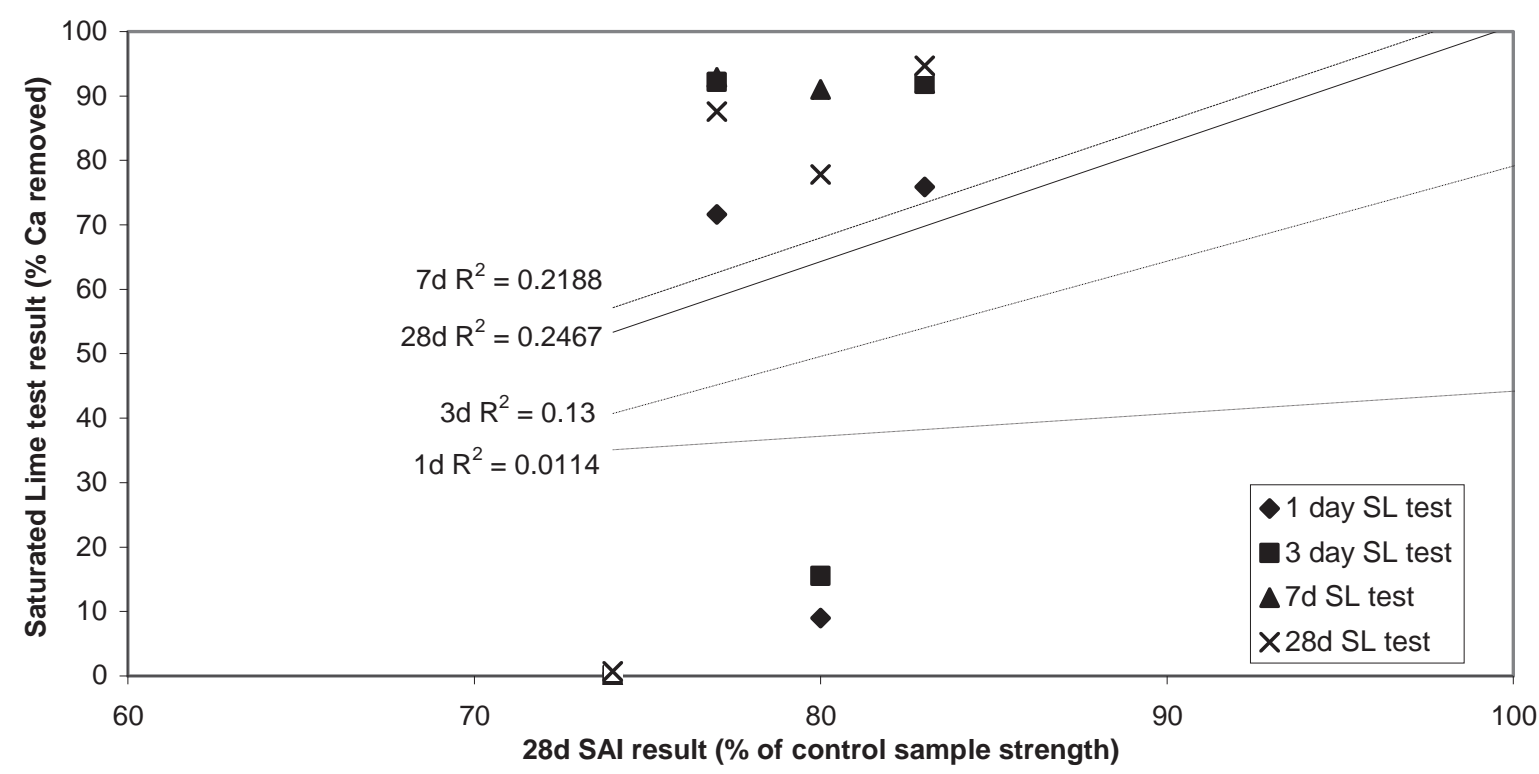

Figure 6 - Correlation between measured pozzolanic activity of 5 test materials using the saturated lime test (at 1, 3, 7 and 28d) and the $28 \mathrm{~d}$ strength activity index test results 


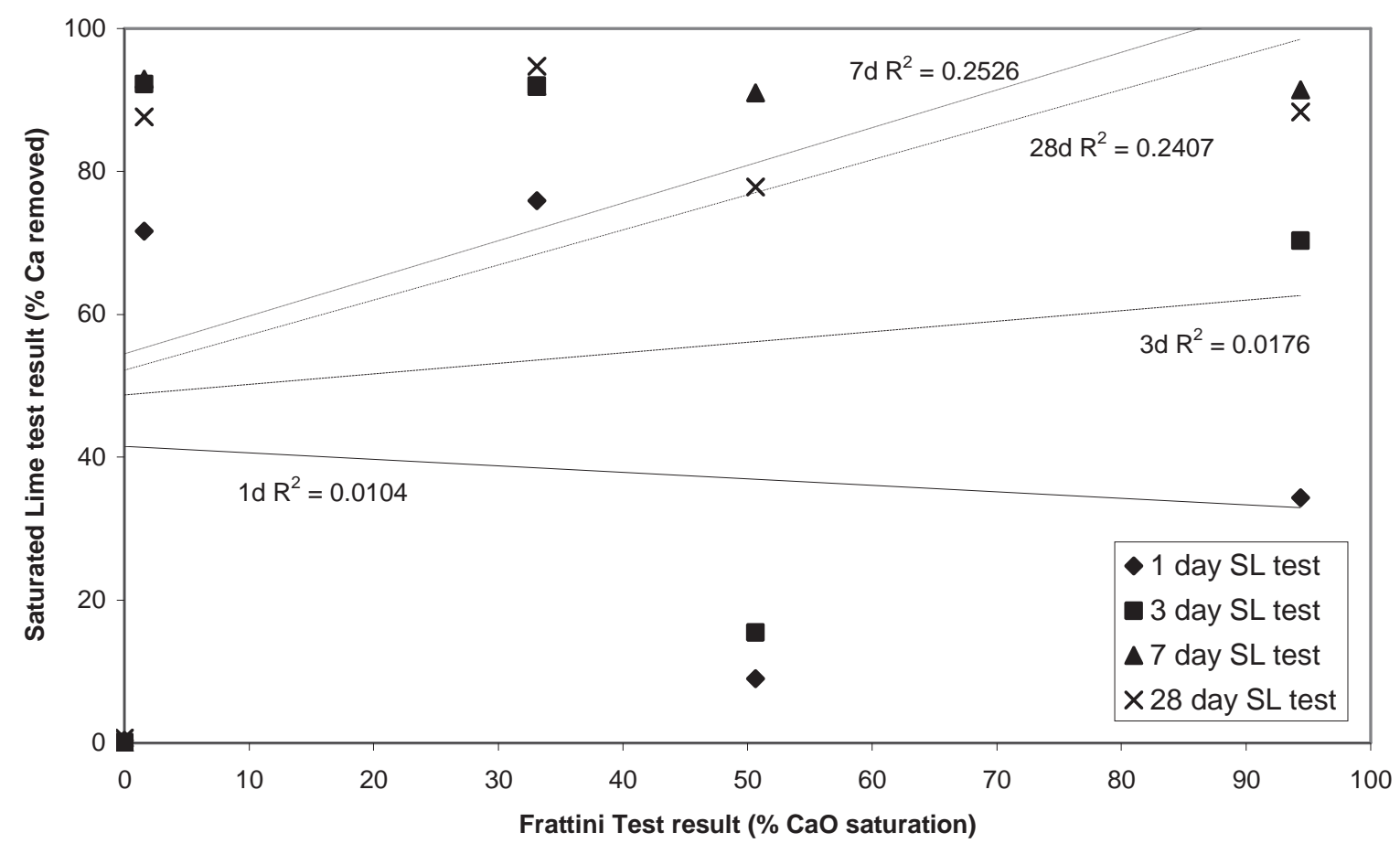

Figure 7 - Correlation between measured pozzolanic activity of 5 test materials using the saturated lime test (at 1, 3, 7 and 28d) and the Frattini test at 8d.

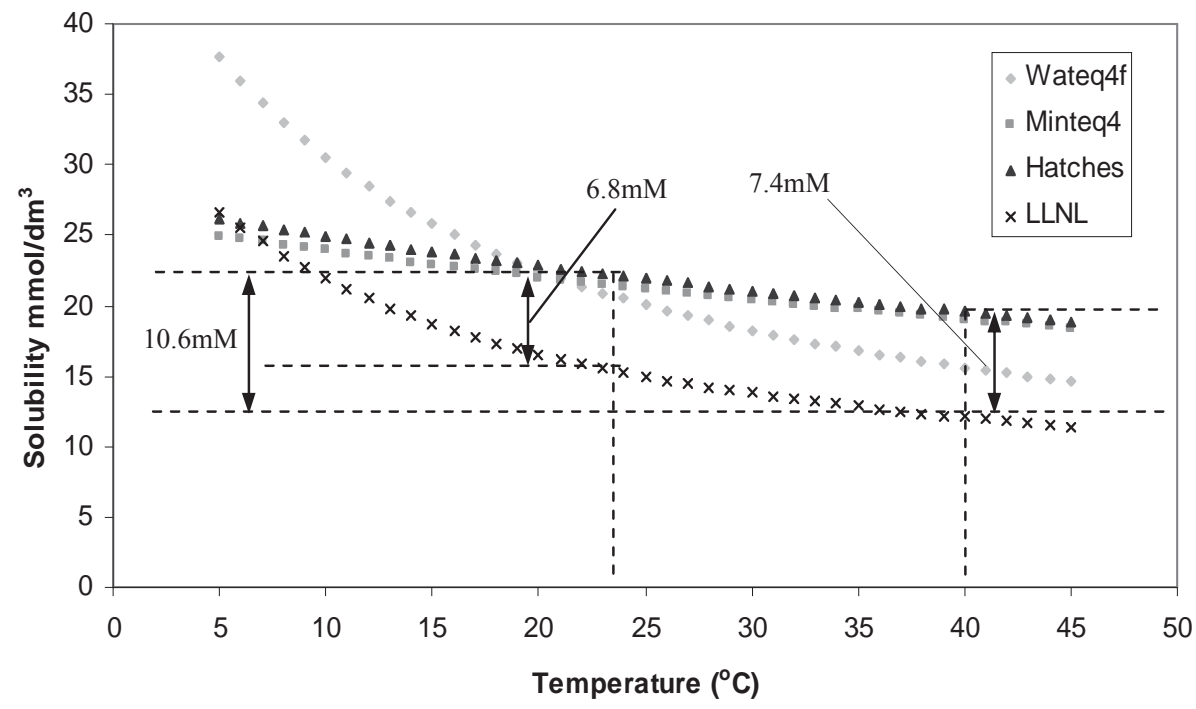

Figure 8 - Predicted solubility of portlandite as a function of temperature, using the thermodynamic code PHREEC-I [21] with four published databases: Wateq4f and Minteq4 contain data supplied with software of the same names. Hatches version 16 (UK) [22] is lodged with the Nuclear Energy Agency whilst the data from the Lawrence Livermore National Laboratory (USA) is supplied with the PHREEQC-I package. 


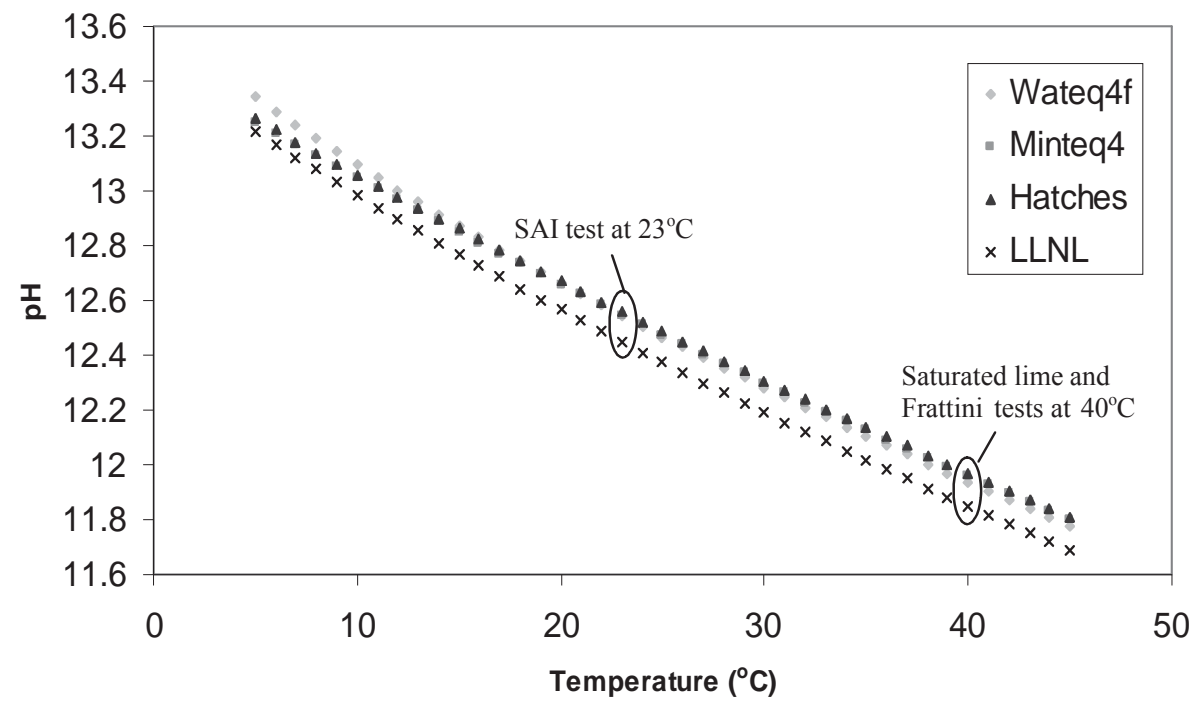

Figure 9 - Predicted $\mathrm{pH}$ of an aqueous solution at equilibrium with portlandite as a function of temperature. Calculation details are identical with those used to plot figure 7. 
Table 1 - Chemical and physical characteristics of five test materials

\begin{tabular}{|c|c|c|c|c|c|}
\hline & ISSA & FA & SF & MK & sand \\
\hline \multicolumn{6}{|l|}{ Chemical composition (\%) } \\
\hline $\mathrm{SiO}_{2}$ & 35.8 & 53.8 & $>97.5$ & 59.5 & \\
\hline $\mathrm{Al}_{2} \mathrm{O}_{3}$ & 11.2 & 27.1 & $<0.7$ & 34.0 & \\
\hline $\mathrm{Fe}_{2} \mathrm{O}_{3}$ & 16.9 & 9.1 & $<0.3$ & 0.7 & \\
\hline $\mathrm{CaO}$ & 12.9 & 2.3 & $<0.3$ & 0.6 & \\
\hline $\mathrm{P}_{2} \mathrm{O}_{5}$ & 11.9 & 0.4 & $<0.1$ & 0.0 & \\
\hline $\mathrm{MgO}$ & 1.9 & 1.2 & $<0.5$ & 0.5 & \\
\hline $\mathrm{K}_{2} \mathrm{O}$ & 1.5 & 3.3 & $<0.6$ & 2.0 & \\
\hline $\mathrm{Na}_{2} \mathrm{O}$ & 0.2 & 0.8 & $<0.3$ & 0.0 & \\
\hline $\mathrm{TiO}_{2}$ & 1.0 & 1.2 & & 0.2 & \\
\hline $\mathrm{SO}_{3}$ & 3.1 & 0.7 & $<0.4$ & 1.1 & \\
\hline Sum & 96.4 & 99.9 & & 99.6 & \\
\hline LOI & 0.8 & 4.3 & $<1.0$ & 0.8 & \\
\hline \multicolumn{6}{|l|}{ Physical properties } \\
\hline $\mathrm{pH}$ & 7.2 & 10.4 & 8.2 & 4.8 & 8.3 \\
\hline Specific Gravity $\left(\mathrm{g} / \mathrm{cm}^{3}\right)$ & 2.43 & 1.97 & 1.94 & 2.14 & 2.20 \\
\hline Loose bulk density $\left(\mathrm{kg} / \mathrm{m}^{3}\right)$ & 700 & 929 & 311 & 285 & 1452 \\
\hline Mean particle size $(\mu \mathrm{m})$ & 140.8 & 31.3 & 21.3 & 6.6 & 113.3 \\
\hline BET surface area $\left(\mathrm{m}^{2} / \mathrm{g}\right)$ & 6.4 & 7.2 & 21.4 & 17.3 & N/A* \\
\hline
\end{tabular}

*the sand was considered too coarse to accurately measure BET surface area

Table 2 - Test mixtures used in the three pozzolanic activity tests

\begin{tabular}{lccccc}
\hline \multicolumn{1}{c}{ Test / material } & $\begin{array}{c}\mathrm{PC} \\
(\mathrm{g})\end{array}$ & $\begin{array}{c}\mathrm{Ca}(\mathrm{OH})_{2(\mathrm{aq})} \\
(\mathrm{ml})\end{array}$ & $\begin{array}{c}\text { Mortar sand } \\
(\mathrm{g})\end{array}$ & $\begin{array}{c}\text { Test pozzolan } \\
(\mathrm{g})\end{array}$ & $\begin{array}{c}\text { Water } \\
(\mathrm{ml})\end{array}$ \\
\hline SAI / Control & 450 & - & 1350 & 0 & 225 \\
SAI / sand & 360 & - & 1350 & 90 & 225 \\
SAI / ISSA & 360 & - & 1350 & 90 & 260 \\
SAI / FA & 360 & - & 1350 & 90 & 234 \\
SAI / SF & 360 & - & 1350 & 90 & 296 \\
SAI / MK & 360 & - & 1350 & 90 & 276 \\
& & & - & & \\
Frattini / control & 20 & - & - & 0 & 100 \\
Frattini / sand & 16 & - & - & 4 & 100 \\
Frattini / ISSA & 16 & - & - & 4 & 100 \\
Frattini / FA & 16 & - & - & 4 & 100 \\
Frattini / SF & 16 & - & - & 4 & 100 \\
Frattini / MK & 16 & - & - & & \\
& & & - & 0 & - \\
Sat. Lime / control & - & 75 & - & 1 & - \\
Sat. Lime / sand & - & 75 & - & 1 & - \\
Sat. Lime / ISSA & - & 75 & - & 1 & - \\
Sat. Lime / FA & - & 75 & - & 1 & - \\
Sat. Lime / SF & - & 75 & - & 4 & \\
Sat Lime / MK & - & 75 & - & & \\
\hline
\end{tabular}


Table $3-8$ day Frattini test results for five test materials quantified using equation 2 .

\begin{tabular}{|c|c|c|c|c|}
\hline Material & $\begin{array}{c}{[\mathrm{OH}]} \\
\mathrm{mmol} / \mathrm{L}\end{array}$ & $\begin{array}{l}{[\mathrm{CaO}]} \\
\mathrm{mmol} / \mathrm{L}\end{array}$ & $\begin{array}{c}\text { Theoretical } \\
\text { max. }[\mathrm{CaO}] \\
\mathrm{mmol} / \mathrm{L}\end{array}$ & $\begin{array}{c}{[\mathrm{CaO}] \text { reduction }} \\
\% \\
\end{array}$ \\
\hline Control & 57.4 & 8.2 & 8.3 & 0.6 \\
\hline sand & 53.8 & 9.9 & 9.0 & -9.6 \\
\hline ISSA & 61.3 & 8.1 & 7.6 & 1.6 \\
\hline FA & 53.2 & 4.5 & 9.2 & 50.7 \\
\hline SF & 35.4 & 11.5 & 17.2 & 33.1 \\
\hline MK & 37.0 & 0.9 & 15.9 & 94.4 \\
\hline
\end{tabular}

